\title{
Development of Pore Pressure and Shear Strain in Clean Hostun Sands under Multi-directional Loading Paths
}

\author{
Mengchen Sun $^{1}$ and Giovanna Biscontin ${ }^{2}$ \\ ${ }^{1}$ Cambridge University, Cambridge CB3 OET, UK \\ ${ }^{2}$ Cambridge University, Cambridge CB3 OET, UK \\ gb479@cam.ac.uk
}

\begin{abstract}
A series of undrained multi-directional direct simple shear tests with circular paths were conducted to investigate the excess pore pressure generation and shear strain development in clean Hostun sands under multi-directional loading condition. The results of an example test are shown. The excess pore pressure accumulation and shear strain development under multi-directional loading condition exhibits evidently different characteristics compared with that under uni-directional loading condition. Excess pore pressure accumulates generally with the circular stress path but can have increase and decrease within a single cycle as well.
\end{abstract}

Keywords: Multi-directional loading, excess pore pressure, liquefaction.

\section{Introduction}

Earthquakes apply three dimensional acceleration. Shear waves propagating upward tend to result in 2D shearing on the horizontal plane. Other types of loading including wave and wind also apply multi-directional loading.

The influence of multi-directional loading was first investigated experimentally by Pyke et al. (1975), who conducted shake table tests to study the settlement of sands. They compared the settlement induced by uni-directional loading and gyratory loading path, and found that the accumulation of settlement under gyratory loading is approximately twice that under uni-directional loading. Since then, data regarding multi-directional shearing remain scarce and the effects of multi-directional loading on sands are far from being fully understood. Though previous studies agree that multi-directional loading tends to result in lower liquefaction resistance, the degree of reduction varies, and the mechanism of this negative effect is still not clear. Therefore, a series of multi-directional direct simple shear tests with circular stress paths were conducted to develop understanding of this issue and the results of an example test will be presented here. 


\section{$2 \quad$ Literature Review}

In terms of laboratory research with respect to soil liquefaction, simple shear apparatuses, which have been utilized successfully in characterizing static and dynamic soil properties, are often preferred, especially when it is desirable to produce a condition where rotation of the principal stress directions occur continuously. Most of the existing simple shear devices, however, can only shear specimens in a single horizontal direction and thus cannot involve multi-directional loading paths, which are the actual loading conditions during earthquakes. To improve this situation, a few multi-directional direct shear devices have been developed, but a rather limited number of multi-directional shearing tests on sands have been conducted.

Ishihara and Yamazaki (1980) developed the first multi-directional simple shear apparatus to investigate the effect of change of loading directions on liquefaction resistance. Further work with this device concluded that rotation of stress directions tends to result in a lower liquefaction resistance (Tokimatusu and Yoshimi, 1982; Ishihara and Nagase, 1988; Fukutake and Matsuoka, 1989).

Kammerer (2002) found that the rotation of stress direction in horizontal plane results in faster generation of pore water pressure, which was explained by the aiding effect of stress rotation on particle rearrangement and densification of soil.

\section{Test Information}

A circular stress path, without initial static shearing, is characterized by constant total shear stress ratio (SSR), which is a huge difference compared with linear stress paths, and is thus considered as a very promising baseline for multi-directional shearing research. A series of undrained cyclic tests with circular stress paths were, therefore, conducted to develop insights into the process of pore pressure generation in multidirectional loading scenarios. A circular-path test with a maximum SSR of 0.2 , which simulates a simplified fundamental multi-directional earthquake scenario, is presented here as an example to illustrate the preliminary findings from this category of tests.

The sand tested is Hostun Sand. The particle size distribution curve is shown in Figure 1, with maximum void ratio of 1.01, minimum void ratio of 0.555 and specific gravity at 2.65 . The relative density of the sample is $63 \%$. The sample has a diameter of $101.6 \mathrm{~mm}$ and a height of $18.8 \mathrm{~mm}$, with a diameter-to-height ratio of 5.4 to minimize the effects of rocking due to the lack of complimentary shear stresses and produce more uniform stress distribution during simple shear tests. The initial vertical stress applied to the sample is $100 \mathrm{kPa}$. 




Fig. 1. Particle size distribution curve for Hostun Sand

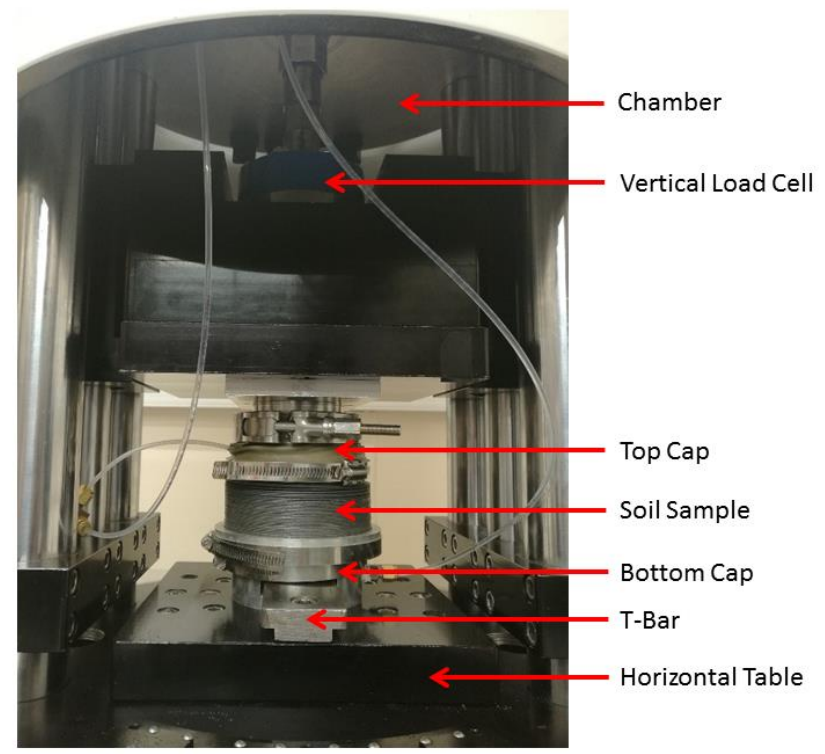

Fig. 2. A photo of the testing device with a sample installed

The multi-directional simple shear apparatus developed by Rutherford and Biscontin (2013) has been recently upgraded and was used for the experimental program described in this study. The testing system has two horizontal tables that can move in perpendicular directions independently for the application of multidirectional shearing. A chamber encloses the specimen allowing air confining pressure to balance back pressure, and excess pore pressure can thus be measured. A stack of lubricated steel rings is employed to confine the sample. A modified top cap 
was designed and used to provide better seal for the sample and prevent gap from developing between the top cap and the rubber membrane when shearing is applied. The photo of the system with a sample is presented in Figure 2, while the schematic of the device can be found in Rutherford and Biscontin (2013). Samples were created using air pluviation, and then flushed with $\mathrm{CO}_{2}$ before being installed onto the testing device to achieve better saturation.

\section{$4 \quad$ Test Results}

As described in the preceding section, the circular loading path of the test starts from point with maximum stress in $\mathrm{X}$ direction, and proceeds anticlockwise. The plan view of measured shear stress is illustrated in Figure 3, with the theoretical path in red. The initial part of the first cycle veers away from the theoretical path because the device needs to synchronize its two loading strokes. When excess pore pressure becomes high, the stiffness of the sample reduces significantly and makes it difficult for the testing device to hold constant vertical stress or good control of shear stress, leading the last few cycles to deviate from the theoretical circular stress path.

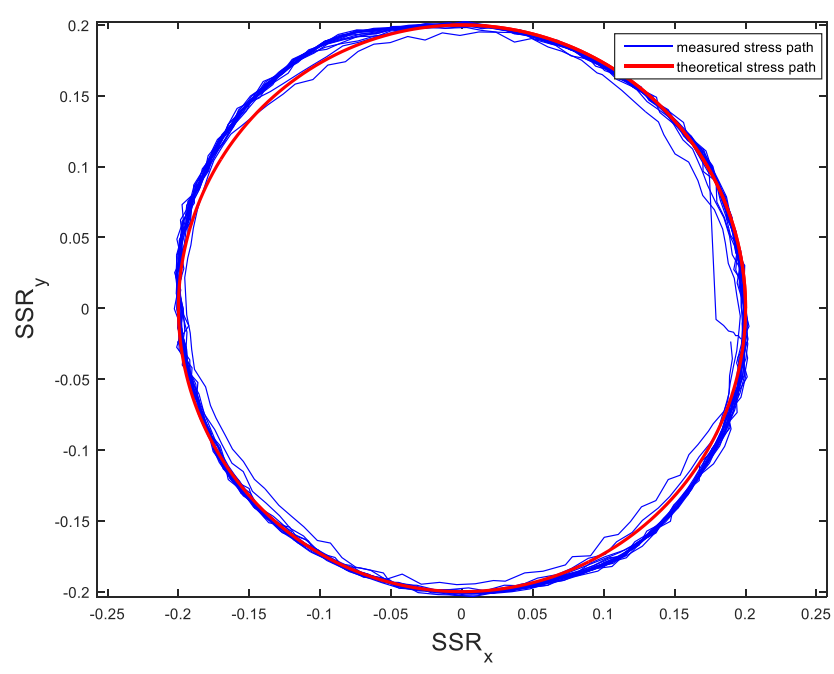

Fig. 3. Plan view of shear stress 


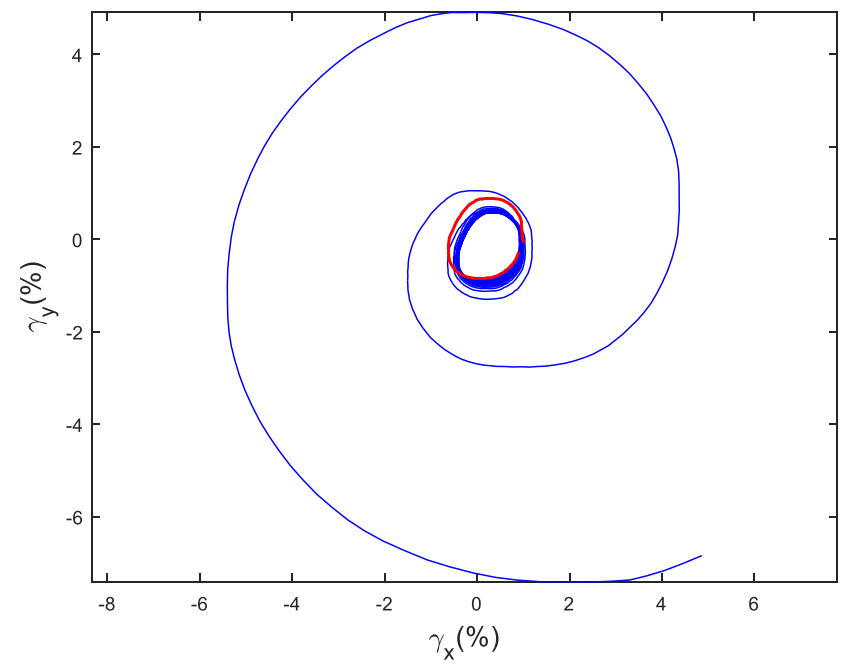

Fig. 4. Plan view of shear strain

The plan view of shear strain is shown in Figure 4, with the strain path of the first cycle in red. X shear strain does not start from zero because the LVDT is not zeroed again after the static loading stage where the $\mathrm{X}$ stress is increased to $20 \mathrm{kPa}$. The whole strain path remains circular generally, as expected, until the sample liquefies. There is a small permanent strain accumulated towards the negative $\mathrm{Y}$ direction, the reason of which is relevant to the excess pore pressure development and will be examined later.

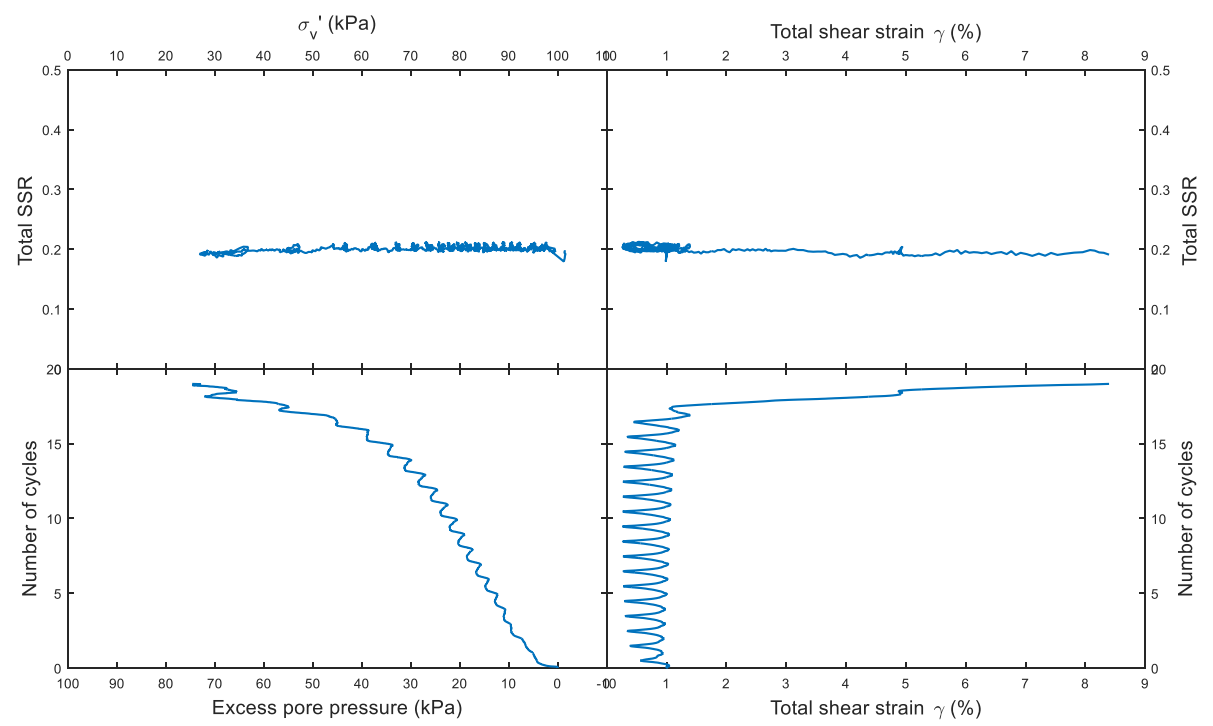

Fig. 5. Four-way plot of the test 


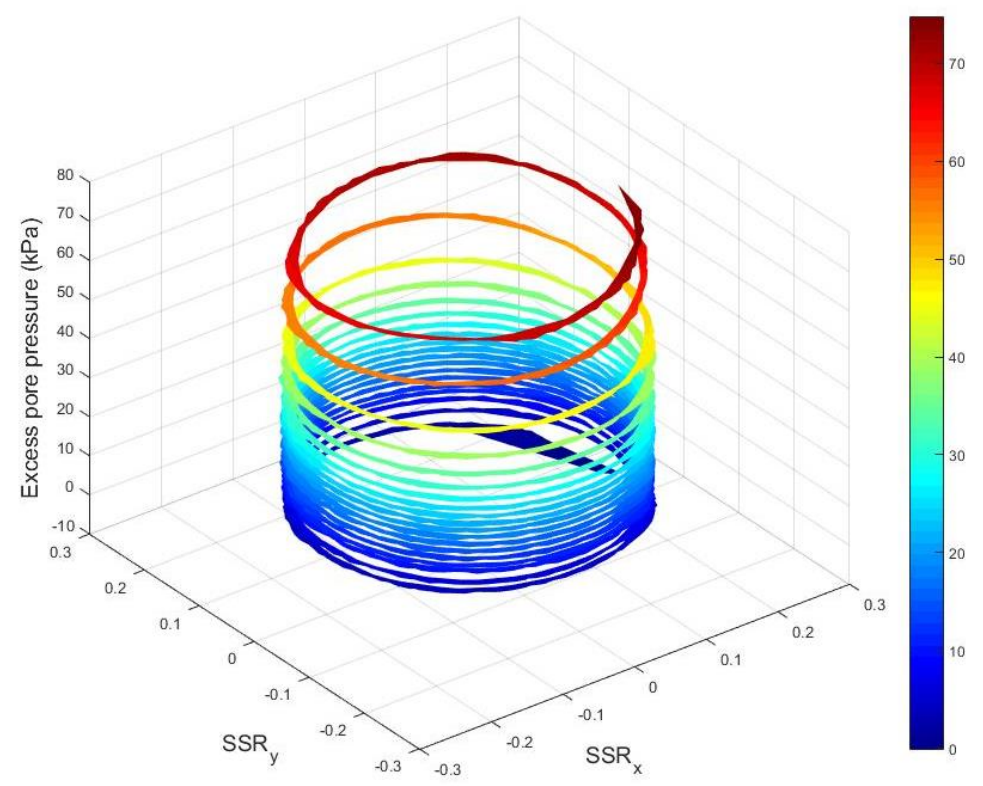

Fig. 6. Excess pore pressure with stress path

A four-way plot (Kammerer, 2002) is shown in Figure 5. The total SSR (defined as equation 1) versus effective vertical stress and the total SSR versus shear strain are almost horizontal, as expected, confirming the total SSR remained constant during the circular path and the testing device performed satisfactorily. The excess pore pressure accumulates gradually and the maximum pore pressure of $72.6 \mathrm{kPa}$ is reached at the 19th cycle when liquefaction occurs.

$$
S S R_{\text {total }}=\sqrt{S S R_{x}^{2}+S S R_{y}^{2}}
$$

Figure 6 shows the development of the excess pore pressure with stress path, and Figure 7 shows the same plot with the red dots representing sections where excess pore pressure increases within a cycle and the light blue dots presenting portion where it decreases. Excess pore pressure accumulates generally as the test proceeds, though it has up-and-downs within a single cycle. When the excess pore pressure is relatively low, it increases along half of the path and decreases in the other half. In this test, excess pore pressure decreases in the semicircle corresponding from $135^{\circ}$ to $315^{\circ}$, and increases in the other semicircle. Figure 8 presents the excess pore pressure of the 5 th cycle of the test. From $0^{\circ}$ to $135^{\circ}$, excess pore pressure increases and reaches the highest point. Then excess pore pressure decreases and reaches the lowest value at approximately $315^{\circ}$. Excess pore pressure then increases again towards the end of this cycle, and it should be noticed that excess pore pressure has a higher value by the end of this cycle compared with the starting point of the cycle. Generally, the semicircle where $\mathrm{SSR}_{\mathrm{y}}$ is negative has higher excess pore pressure than the other, and thus a 
lower effective vertical stress. Since a lower effective overburden means a lower strength for sands, the sample is weaker in the $\mathrm{SSR}_{\mathrm{y}}$ semicircle, and some permanent shear strain develops. Thus, permanent shear strain is observed to accumulate towards the negative $\mathrm{SSR}_{\mathrm{y}}$ direction, as described in the preceding section. This observation agrees with Kammerer's (2002) observations.

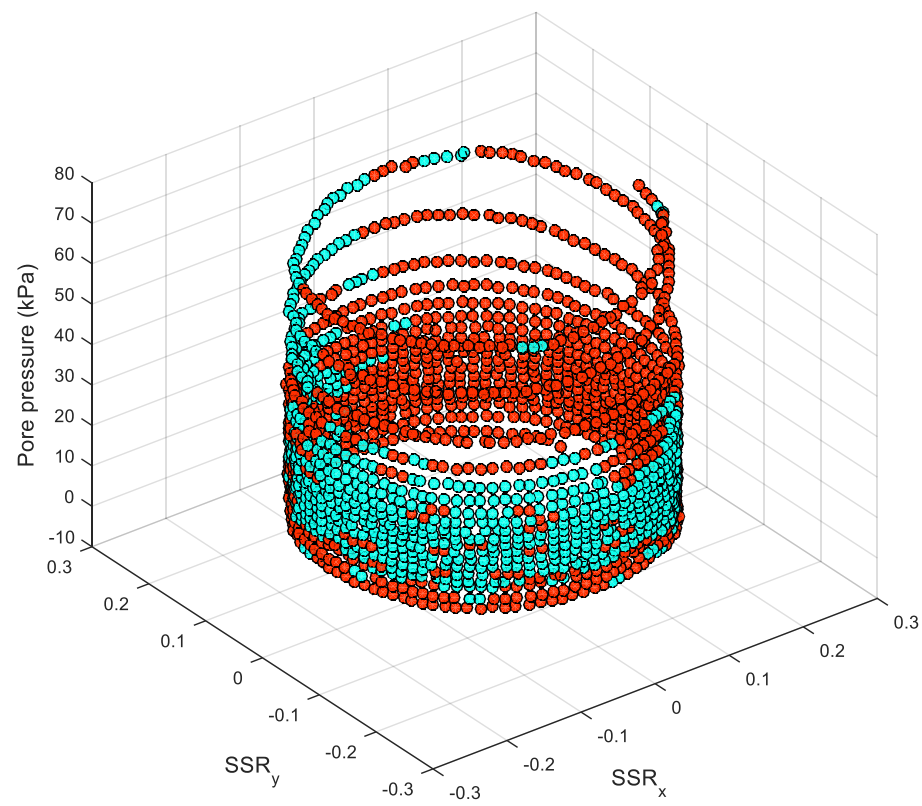

Fig. 7. Increase and decrease of excess pore pressure

Although the testing procedure in other tests is consistent with the description above, the portion of the cycle in which excess pore pressure is cycling from positive to negative is not always the same. The mechanism behind this inconsistency is yet unclear. One possible explanation attributes it to loading asymmetry due to the slight variations from a perfect circle. More tests and more careful investigation with respect to this issue are under way. 


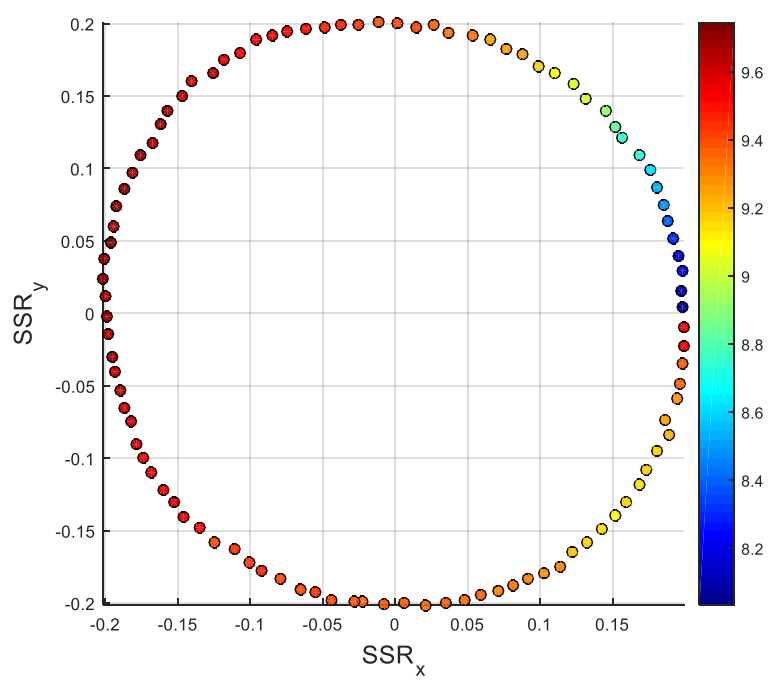

Fig. 8. Excess pore pressure of the 5th cycle

\section{References}

1. Fukutake, K. \& Matsuoka, H.: A unified law for dilatancy under multi-directional simple shearing. Doboku Gakkai Ronbunshu 412, 143-151 (1989)

2. Ishihara, K., \& Nagase, H.: Multi-directional irregular loading tests on sand. Soil Dynamics and Earthquake Engineering 7(4), 201-212 (1988).

3. Ishihara, K. \& Yamazaki, F.: Cyclic simple shear tests on saturated sand in multidirectional loading. Soils and Foundations 20(1), 45-59 (1980).

4. Kammerer, A. M.: Undrained response of Monterey $0 / 30$ sand under multidirectional cyclic simple shear loading conditions (Doctoral dissertation, University of California, Berkeley) (2002).

5. Pyke, R. M., Chan, C. K., \& Seed, H. B.: Settlement of sands under multidirectional shaking. Journal of the Geotechnical Engineering Division 101(4), 379-398 (1975)

6. Rutherford, C. J. and G. Biscontin: Development of a Multidirectional Simple Shear Testing Device. Geotechnical Testing Journal 36(6), 858-866 (2013).

7. Tokimatusu, K. \& Yoshimi, Y.: Liquefaction of sand due to multidirectional cyclic shear. Soils and Foundations 22(3), 126-130 (1982). 